\title{
LA PRENSA CATÓLICA EN EL ESTADO SOBERANO DEL MAGDALENA: GUERRA DE PALABRAS Y PEDAGOGÍA POLÍTICA
}

\begin{abstract}
Adriana Santos*
La prensa en el Estado Soberano del Magdalena, esto es, los periódicos, pasquines, cartillas y hojas volantes, divulgaron las propuestas de la élite política nacional y regional tanto liberal como conservadora bajo características específicas que oscilaron entre una guerra informativa tendiente a consolidar una forma particular de hegemonía cultural y la formación de una opinión pública producto de la educación. Aunque en la retórica sobre el proyecto de las publicaciones periódicas se trazaba como propósito fundamental la educación de los ciudadanos, en el plano de los principios políticos liberales o conservadores, en realidad no siempre se cumplió con dicha meta. Con frecuencia, se hizo uso de un lenguaje cargado de adjetivaciones que coadyuvó al conflicto -incluso armado - entre los distintos sectores políticos. De esta manera, la prensa del Magdalena, al igual que en otras regiones de la Unión, hizo parte del conjunto de instituciones y acciones dirigidas a estigmatizar al adversario político. Sus esfuerzos se orientaron a reforzar la imagen del contrario político enmarcada en la relación irreconciliable amigo-enemigo. ${ }^{1}$ Su tarea consistió en una "ofen-

\footnotetext{
* Magister en Historia. Profesora Universidad del Atlántico. Ponencia leída en el IV Seminario de Historia del Caribe Colombiano, realizado en Cartagena entre el 29 de mayo y el $1^{\circ}$ de junio de 2001 . intransigencia de la diócesis de Tunja. Bogotá: Ministerio de Cultura, 1998. El autor hace uso del concepto de "intransigencia" para referirse a las actitudes excluyentes de los
}

1. En este sentido ver José David Cortés. Curas y Políticos. Mentalidad religiosa e
\end{abstract}


si va ideológica" que tuvo como objetivo moldear los comportamientos y opiniones de la población civil frente a su antagonista liberal o conservador. En otras palabras, además de los numerosos conflictos armados, se dio una guerra informativa.

La prensa conservadora o liberal buscó imponerse sobre la otra mediante la formación de una "opinión pública" azul o roja que se definía como "católica" ó "liberal pura", aunque no en el sentido moderno. ${ }^{2}$ Los editores de periódicos usaron, planificadamente y con una orientación determinada, el contenido de los escritos publicados. En algunas ocasiones utilizaron referentes tales como la exposición sistemática de sus programas; mientras que en otras, echaron mano de acciones, imágenes, símbolos y lenguajes tendientes a influir en la sensibilidad y reacción de sus lectores. La prensa se utilizó abiertamente como un instrumento para hacer política, entendida como la posibilidad de permear en el cuerpo social y así transmitir y reproducir los mensajes acerca de su colectividad y de sus enemigos. El quehacer de los diarios osciló entre la publicación creciente de artículos con una "radicalización progresiva del lenguaje",3 y la exposición explícita de conceptos políticos.

En este sentido, las siguientes líneas examinarán la manera en que la prensa católica del Estado Soberano del Magdalena buscó la defensa de la religión, de la jerarquía eclesiástica y del partido conservador.

diferentes sectores políticos y de la Iglesia a la cual denomina como representante del "catolicismo intransigente". Además dedica uno de sus capítulos a tratar el modo en que la prensa se convirtió en una herramienta de combate religioso.

2. Se hace referencia a la inexistencia de una opinión pública a la manera como es definida por Francois Guerra: como la expresión pública de las ideas que permite la libre discusión sobre toda temática, incluida la política. La opinión pública moderna existe cuando "empieza a erigirse en una instancia moral independiente del Estado que juzga, en nombre de la "razón", la validez no sólo de las medidas del gobierno, sino también de los principios generales que deben regir a la sociedad". Francois Xavier Guerra. Modernidad e independencias. Ensayos sobre las revoluciones hispánicas. México, Fondo de Cultura Económica, 1992, p. 228.

3. Expresión utilizada por el mismo Francisco Xavier Guerra. 


\section{TÁCTICAS EN COMÚN: PRENSA CATÓLICA Y LIBERAL EN LA BÚSQUEDA DE LOS MISMOS OBJETIVOS}

Resulta interesante, a pesar de las altas tasas de analfabetismo, la cantidad de folletos y pasquines que se han encontrado en donde cada individuo o sector político expone sus puntos de vista, razones y justificación de sus acciones. ${ }^{4}$ Así las cosas, el contenido de los periódicos se difundió a través de la lectura en grupo para favorecer a quienes no sabían leer; por tanto, la prensa se leía por el sacerdote, por los líderes políticos y por los padres de familia. En realidad, estas publicaciones más que difundir noticias e informar sobre los últimos acontecimientos se orientaban hacia objetivos específicos tales como defender o atacar tal o cual candidato a cualquier cargo, criticar o apoyar las diferentes posiciones ante la religión y las instituciones católicas así como mostrar sus preferencias sobre la instrucción pública, sus orientaciones y contenidos.

Para alcanzar los objetivos antes mencionados, dichas publicaciones, sin importar la filiación partidista, tuvieron en común algunas características. En primer lugar, durante los períodos de elecciones las publicaciones aumentaban. Se trataba de los llamados periódicos eleccionarios, cuyo período de vida duraba el tiempo de la campaña electoral. En los editoriales de dichas publicaciones, se declaraba abiertamente la adhesión a uno de los candidatos, se incluían discursos de partidarios, se hacían comentarios

4. En diez años comprendidos entre 1869 y 1879 se encontraron periódicos liberales como El Adelantado de Santa Marta publicado en 1874; El Correo editado en Santa Marta durante 1878; la Unión Liberal publicado en Santa Marta en el año de 1870; Registro del Magdalena que circuló en Santa Marta durante 1879. Unos años más adelante se registraron publicaciones como El Celador (1880); El Repertorio Eclesiástico (1880); La Revista enRiohacha (1880); El amigo del Pueblo (1883); El Eco del Magdalena (1884). Los periódicos que circularon a través de la acción de la Iglesia fueron " $L a$ Unidad Católica" y "El Tradicionista". Librillos y publicaciones de los mensajes escritos a los organismos del gobierno por parte del Obispo Romero se encontraron once. Finalmente, también es frecuente encontrar panfletos y hojas editadas en donde se aclaran hechos relacionados con conflictos individuales. De éstos se encontraron cuatro. 
sobre los acontecimientos sucedidos tanto en la campaña que se defendía como a la que se hacía oposición así como también se respondían los panfletos y las demás afirmaciones hechas por los opositores. En este sentido, durante el siglo XIX y concretamente, bajo el radicalismo, los periódicos se constituyeron como un "medio de movilización electoral" efectivo. ${ }^{5}$

Otros periódicos, en cambio, se crearon como medios de expresión oficiales de los católicos, los conservadores, los radicales, la instrucción pública y los liberales en oposición. Dado este carácter, su publicación fiie más asidua y duradera. En común tuvieron su interés por mantener cohesionado el grupo social del cual tomaron la vocería, desconocer a sus adversarios como interlocutores y convertir los debates en conflictos. Es decir, tanto liberales como conservadores, radicales como liberales independientes y jerarquía eclesiástica informaron a sus partidarios presentan-

5. Alonso Valencia Llanos. Luchas Sociales y Políticas del periodismo en el Estado Soberano del Cauca. Colección de autores vallecaucanos. Cali: Imprenta Departamental del Valle, 1994. El autor señala que "La efectividad política de la prensa decimonónica no se mide únicamente por la capacidad de socializar proyectos políticos o sociales. Ella se mide también por los resultados electorales del grupo político que lidera el periódico. Esto parece obvio ante el hecho de que la coyuntura que dio origen a la mayoría de los periódicos fueron generalmente de carácter electoral”, p. 73. En el caso del Magdalena y para entrar a comparar el tipo de publicaciones de cada uno de los partidos, vamos a citar a continuación el caso de un periódico liberal. En la campaña de 1864 en la ciudad de Santa Marta se publica "El Elector", en cuyo primer ejemplar de junio 8 se declara partidario de la candidatura de Herrera y contradictor de Tomás E. Abello. Su contenido es netamente "eleccionario", como el mismo editorial lo señala. Sustentan su opción por José María L. Herrera y hacen perfiles detallados de su candidato. En un número más adelante publican un artículo que llaman "La Cartilla del Pueblo", en donde a manera de los textos escolares, se recogen una serie de preguntas y respuestas sobre la candidatura de José María L. Herrera. Se trata de un cuestionario sobre las razones para votar por dicho candidato, las obras realizadas durante toda su carrera como político, sus triunfos militares y su compromiso con la instrucción primaria. Una de las preguntas decía "Decidme ciudadano: ¿Por qué votáis por el jeneral José M. L. de Herrera para presidente del Estado?". La respuesta indicaba "porque es honrado/ porque es intelijente/ porque es instruido/ porque es enérjico en el ejercicio del poder público/ porque es valeroso y humano/ porque es tolerante/ porque no transije con sus adversarios/ porque es hombre de convicciones profundas/ porque espera en el triunfo de la verdad política la redención de los pueblos". Periódico El Elector. Estado Soberano del Magdalena. Santa Marta, junio 8 de 1864. 
do una imagen de los opositores como enemigos irreconciliables. Todos y cada uno de estos actores hicieron suyo el discurso de la intransigencia que está basado en la exclusión. ${ }^{6}$

De esta manera, hacia 1874, el periódico conservador $E l$ Tradicionista se plantea como objetivo “...crear en la prensa un representante de los intereses católicos en sus ineludibles relaciones sociales y políticas..." ${ }^{, 7}$. En el momento de referirse a sus contradictores se lee:

En cuanto al partido liberal, de él no aguardamos sino odio u guerra; si dejase de odiar dejaría de existir, porque el odio está en su naturaleza; si dejase de perseguir, dejaría de ser consecuente con sus odios... El es prudente, él se acomoda a los tiempos y sabe que a veces es más fuerte la maña que la violencia. Furiosos unas veces, se apoderan de los sacerdotes y los matan; cautos otras, avocan a sí el derecho, el tremendo derecho de enseñar, y haciendo una propiedad de la infancia, la envenenan con el error. En suma: el partido liberal es esencialmente satánico y anticatólico. ${ }^{8}$

Además de lo mencionado anteriormente, los periódicos sin importar de qué tendencia sean, coinciden en el planteamiento de sus objetivos. Estos son presentados formalmente en la edición del primer número de la publicación y son reiterados permanentemente en los editoriales. Así, publicaciones de muy distinta orientación coinciden en el momento de tomar banderas como el patriotismo, la defensa de las instituciones y el Estado, buscar el bienestar del país y de la sociedad y hacer posible la civilización, así como en su compromiso aparente - o mejor en el discurso- de hacer caso omiso a las posiciones sectarias y de viejas rencillas.

Las diferencias, entonces, se encontraban en la connotación y el significado que cada quien le daba al término "progreso", así

6. A este respecto ver José David Cortés. Op. cit.

7. El Tradicionista, Año III. Trimestre I, número 269. Primero de enero de 1874, p. 1.195.

8. Miguel Antonio Caro. Obras. Tomo 1. Filosofía, Religión, Pedagogía. Bogotá: Instituto Caro y Cuervo, 1962, p. 757. 
90 EL TALLER DE LA HISTORIA 2

como en el papel que cada sector social jugaba en el proceso de alcanzarlo. Mientras que para los radicales el progreso implicaba la secularización de la sociedad y el control estatal de algunas instituciones como la educación y los cementerios, para la Iglesia Católica el mismo término implicaba la conversión de la sociedad a los preceptos católicos y la presencia de la Iglesia en el manejo de algunas de las instituciones sociales, tales como la educación; mientras que para el partido conservador "la dicha y bienestar de los pueblos" se fundamentaba en la "moralidad de los hombres públicos", entendiendo por ésta "saber gobernarse a sí mismo". 9

\section{EL PERIODISMO RELIGIOSO: FORMACIÓN DE BUENOS CRISTIANOS Y RESPUESTA A LOS IMPÍOS}

Al mismo tiempo que se recomendaba la lectura de la prensa de Bogotá $^{10}$, también se propuso la edición de periódicos regionales que se convertirían en los voceros de la Iglesia Católica del

9. Ibid. p. 723.

10. Principalmente se recomendó el periódico "El Tradicionista” dirigido por Miguel Antonio Caro; publicación que se convirtió en el órgano informativo de dicho partido y cuyo contenido se acogería a las orientaciones dadas por Roma - a través del Syllabus - para los partidos católicos. En sus artículos se encuentran referencias continuas al pasado católico de la mayoría de los pobladores de la Unión, la justificación de la necesidad de fortalecer la unidad de todos los católicos para participar en bloque en el devenir político, la estrecha relación entre Iglesia y política, la defensa de la toma del gobierno para construir una república católica cumplidora de los preceptos cristianos así como una crítica a la educación "atea y materialista" impulsada por los radicales. En últimas Caro, según la opinión del Obispo de Santa Marta de la época, “...hace cada vez más explícito y como siguiendo un plan pensado de antemano va llevando al lector a hacer suyas las soluciones del periódico"; por lo que se puede afirmar que detrás de El Tradicionista evidentemente existió la intención de formar ciudadanos conservadores y católicos. En este periódico se dejó de lado un poco el carácter eleccionario y se concentraron en impulsar, a través de sus páginas, una campaña de educación basada en los principios católicos; que surgiría como contrapropuesta al sistema educativo impulsado por los radicales a partir del Decreto Orgánico. Se trataba de oponer una educación cristiana al proyecto de educación, considerada por los conservadores y un sector del clero, como "corruptora", "satánica" y "anticatólica". 
Magdalena. Este hecho encuentra asidero en la lectura que hacía el obispo Romero de la situación vivida por su Diócesis, a partir del acceso al poder por parte de los radicales así como a las ideas pregonadas en los periódicos liberales. En su opinión, los "elementos del desorden" y "los principios subversivos" se desencadenaron en la sociedad "pregonadas por una prensa atrevida e insensata". Así "...el benéfico padre de la cristiandad sufre los horrorosos tormentos de los insólitos corifeos del progreso actual, (subrayado del documento)". .

Ante dicha situación, la salida planteada por Romero debía girar en tomo a "la enseñanza de la juventud", e invitaba a "quitarles a los impíos el medio de propagación de sus doctrinas..." y enseñarles las verdaderas bases y los ciertos fundamentos sobre los cuales descansa el orden social". ${ }^{12}$ Así, en el discurso del Obispo Romero aparecían unidos y estrechamente ligados la prensa y la educación:

La imprenta, esa preciosa invención, se le ha entregado a la inexperta juventud para que escriba contra la relijión i sus dogmas sacrosantos. Se debe propender a la enseñanza en todos sus ramos, establecer escuelas e institutos para ilustrarla en las máximas de la Relijión Católica, en el conocimiento de las ciencias Intelectuales; en las matemáticas, i en otro ramos del saber humano a que podamos contribuir. I si los Estados por cuenta de la Nación envían cierto número de jóvenes a la Universidad de Bogotá, para que más tarde sean redactores del "Tolerante" del "Racionalista i de la "Revista de Colombia". ¿Por qué no trabajar los párrocos, con solicito interés para que los padres de familia nos presten su eficaz apoyo, mandando sus hijos a recibir una sólida instrucción de acuerdo con sus creencias católicas? Así lo aguardamos ${ }^{13}$. (Subrayado nuestro).

11. Archivo Eclesiástico del Magdalena (AEM). Tomo 108. fol. 55. Enero 6 de 1876.

12. Ibid.

13. A.E.M. Tomo 90. fol. 30. Año de 1874. Los radicales hacían énfasis en el tema de la tolerancia como mecanismo para mostrarse víctimas de persecuciones religiosas. De allí el nombre "El Tolerante" para un periódico. Romero criticaba esta utilización y 


\section{EL TALLER DE LA HISTORIA 2}

Así las cosas, la prensa católica surgió como un contradiscurso al proyecto político y educativo de los radicales. En el Magdalena, dicho contradiscurso fue liderado por el obispo Romero, quien en carta a los vicarios - que fue reproducida para hacerla circular entre los "buenos cristianos" - señalaba:

Si los escritores heterodojos difunden sus periódicos en las ciudades, pueblos y aldeas, también nosotros debemos hacerlo con los periódicos que se han encargado de la noble empresa de rechazar i evidencias esas producciones asquerosas contra la santa relijión enseñada por el Dios-Hombre; i asi como los impíos y los materialistas ${ }^{14}$.

Hacia finales de 1869, Romero decidió crear un periódico que circularía mensualmente en todo el Estado y le serviría de elemento de doctrina católica, información y medio para animar la defensa de la Iglesia y sus funciones sociales. Este se logró imprimir por primera vez en el mes de enero de 1870. La suscripción de los fieles y párrocos cercanos a la curia debía ser obligatoria y el valor recogido debía enviarse a José Antonio Acosta, editor del periódico. Es así como la Unidad Católica se convirtió en el medio de expresión de las ideas y luchas de la Iglesia y el obispo Romero contra las medidas de los radicales ${ }^{15}$.

En lo que se refiere a los periódicos, los sacerdotes católicos sentían que los radicales estaban destruyendo, poco a poco, con

\footnotetext{
y señalaba el carácter de la tolerancia proclamado por los liberales "discípulos de Voltaire y Rousseau” como “...tolerancia para el error, para la vejación del Derecho, para combatir las creencias católicas i para desobedecer a la autoridad; en una palabra, tolerancia para hacer cuanto plazca a las. pasiones e intereses propios. En sus argumentos nos repiten, LIBERTAD DEL PENSAMIENTO pero es solo para ellos i así, los vemos intolerantes para con el catolicismo, para con las creencias i las artes i hasta intolerantes en las cuestiones sociales: déspotas i tiranos del pensamiento subordinado únicamente a las leyes de Dios, tratan de sustraerlo de esta obediencia lejítima para someterlo a sus ambiciones i caprichos". Tomo 108. Folios 105 y 139. 1875. Según el obispo no se podía hablar de tolerancia cuando se atacaba al catolicismo y su enseñanza en las escuelas primarias.
}

14. Tomo 90. Folio 110. Enero 1 de 1872. Volumen II.

15. La idea del periódico propuesta por Romero, en julio de 1869, es aceptada por el arzobispo de Bogotá. 
sus medidas, las redes de sociabilidad que permitían a éstos controlar a la población civil. Más allá del debilitamiento económico, la pérdida del control social afectaba aún más al clero. Por ello, las justificaciones frente a las políticas liberales exaltaban la labor de la Iglesia en la formación de la nación, la educación y la "civilización" de un pueblo ignorante y violento. En este sentido, el párroco de Ocaña le escribe a Romero una carta, donde se puede inferir lo que pensaban los curas a nivel local sobre el papel jugado y por jugar por la Iglesia Católica. Manuel J. Manjarrés afirmaba que veía con gravedad el hecho que se encargaran misioneros protestantes de la instrucción ya que:

...sabemos que hasta en los libros para enseñar idiomas se encuentra impregnado el veneno de sus erróneas doctrinas y vienen a nuestra patria con la mira de arrastramos a sus reformas, pues de seguro no irán a Casanares, la Goajira, el Opón y el Darién a convertir a los indios salvajes. Mas no es solamente esto lo que deploramos; la prensa llamada a civilizar en el sentido perfecto de esta palabra, ha tomado por su cuenta la enojosa tarea de atacar con cínico descaro los dogmas católicos; i todo lo más santo i sagrado sometido a la burla i el escarnio ${ }^{16}$.

La forma, según el prelado, era "levantar la voz para excitar a nuestro clero se muestre vigilante i redoble sus esfuerzos en la lucha". Manjarrés reconocía, al igual que otros, la importancia de la prensa e invitaba a aprovecharla:

Los impíos i materialistas, los inventores de sistemas de moral, sostienen i circulan aquellas publicaciones, es preciso, es indispensable, de que a la vez el clero, i los buenos católicos; apoyen i propaguen con su influencia, con su ilustración i dinero al periodismo relijioso. Deseamos la sólida ilustración de la juventud i el progreso de nuestra patria; pero una i otro fundados en el catolicismo porque todo saber humano que no esté basado en el temor de Dios, es pernicioso i de funestas consecuencias ${ }^{17}$.

16. A.E.M. Tomo 102. s.f. Enero 1 de 1872.

17. Ibid. 


\section{EL TALLER DE LA HISTORIA 2}

Se tiene, entonces, que parte de las consignas, directrices, diatribas, recusaciones y defensas del catolicismo se transmitían a través de la prensa. Para ello, Romero mantuvo la publicación de un periódico que circulaba semestralmente durante dos años, aunque su elevado costo, lo obligó a adaptar para sus intereses unos cuadernillos de dos hojas (cuatro páginas) donde escribía para sus fieles, de los cuales se hablará más adelante.

Aún así, Romero consciente del poder de las letras decidió fundar otro periódico denominado "Repertorio Eclesiástico el cual, a partir de 1876, funcionaría como el órgano oficial de la diócesis. Allí se expresarían directa y asiduamente las ideas de Romero así como las directrices trazadas a nivel nacional entre conservadores, clero y los nuñistas, sectores que hicieron alianza en este momento.

En esta ocasión, la aparición del periódico encuentra asidero en argumentos como la pérdida de respeto a la ley moral y los "altares" levantados a la "diosa razón"; pero, sobre todo, en la necesidad de que los curas se informaran para que cumplieran con su misión regeneradora. Así, el periódico sería nuevamente un instrumento para la formación: "Hay que oponer a la falsa enseñanza la enseñanza verdadera; y para esto, los llamados particularmente a darla, es decir, los sacerdotes, deben entregarse al estudio profundo de los diferentes ramos científicos, sin dejar de corregir al mismo tiempo ese indiferentismo tan soñador que se deja ver en las presentes generaciones"18. Romero insiste en el artículo de presentación del periódico en que "El clero debe conocer bien esta ciencia para defender las verdades católicas para presumirlas del ataque del materialismo y salvar a la incauta juventud de las garras de este moderno león bárbaro y despiadado". ${ }^{19}$

Este pensamiento antiilustrado sería una de las bases de la crítica de la Iglesia. Se asociaba el tema del racionalismo con el 
materialismo; este último se emparentaba sin ningún juicio crítico, con el liberalismo de Bentham.

\section{LIBELOS, PANFLETOS Y CARTILLAS: LA CRÍTICA DE ROMERO AL PROYECTO RADICAL}

Además de los periódicos, el obispo Romero utilizó otros mecanismos para difundir el pensamiento de la Iglesia contra los gobiernos radicales y sus medidas políticas. En dichos escritos se jugaba tanto con el lenguaje peyorativo y maniqueo como con la crítica más elaborada a la propuesta radical.

Uno de los escritos más destacados fue "La verdad y los Sofismas En esta "cartilla católica" de más de seis páginas se condensa el pensamiento y la ideología de la Iglesia frente a las reformas liberales y se atacaba la Ilustración, el racionalismo y los procesos de secularización a través de los cuales el Estado buscaba despojar a la Iglesia Católica del control de la vida pública y privada de la sociedad.

En primera instancia, se hace una defensa de la religión y la moral como base de la sociedad y de "cualquier sistema político" que busque "hacer feliz al pueblo"; por lo que se hace énfasis en "la instrucción moral y religiosa de la juventud, para la cual se requieren la libertad e independencia de la Iglesia,"20.

Otro aspecto que se abordó, por cuanto creaba discordias entre el clero y radicales, era la interpretación y apoyo que daban estos últimos al concepto de ley. Los radicales basaban sus propuestas en el concepto roussoniano de soberanía popular y de la capacidad de legislar que tenían los elegidos para estas corporaciones, por encima de la ley divina. De allí que la ley fuera deno-

minada como "monstruosa" y amañada. El clero no se explicaba cómo el gobierno pregonaba la libertad de cultos, pero atacaban y 


\section{EL TALLER DE LA HISTORIA 2}

participaban contra un credo y sus representantes: el catolicismo. Por ello en dicho folleto se aclaraba que si se estaba en "una nación que profesa como cañón sagrado fundamental la prescindencia absoluta del gobierno en asuntos religiosos, ésta era una imponderable mentira". En estos términos se plantea una discusión sobre la ley de tuición propuesta por el secretario de relaciones exteriores y piden pmebas sobre afirmaciones tales como el abuso que el clero hacía de las conciencias. ${ }^{21}$

Otro argumento contra los liberales radicales era el de catalogarlos de masones. En últimas, eran pocos los radicales que tenían relación con la masonería y utilizaban estas estigmatizaciones como mecanismo de defensa y para mostrarse poseedores de un credo moderno y europeísta. Para Romero, la característica esencial de los masones era "el nunca desmentido odio que ellos tienen a la religión católica, las lipaduras que ponen a la verdadera enseñanza de la juventud y el empeño pertinaz que toman en trastornar la noción cristiana de lo justo, lo útil y lo honesto. Para enfrentar a la secta: la educación cristiana de la juventud" 22 . Así, en un acto de malabarismo verbal los radicales del Magdalena se convertían en miembros de la masonería. Sarcásticamente vinculaba a los radicales con la masonería y, en un juego de palabras, los comparaba con enviados de Satán.

De lo anterior se desprende la necesidad de un enfrentamiento y de la recuperación de fuerzas para "renovar la lucha". En ese

21. A este respecto Romero escribía: "Los discípulos del liberalismo, verdaderos perturbadores del orden moral, desconocido ya por Epicuro, quien lo reducía todo al derecho del más fuerte, creen todo igualmente lícito, y hacen creer a los ignorantes y a los amantes del goce que el clero abusa del confesionario para imponer a los penitentes la obligación de resistir al poder temporal con el fin de que el catolicismo ensanche sus dominios, es pues muy conveniente y necesario que el pueblo entienda esto para que donde quiera que encuentre u oiga de boca de los maestros de la civilización moderna las palabras: Tolerancia de cultos, lea y entienda de este modo: iguerra al catolicismo! Si se duda, examínese un poco la conducta del gobierno para con la Iglesia, y se encontrará la teoría de su ley en palpable contradicción con los hechos". Ibid.

22. Ibid. 
sentido, la Iglesia hace un llamado a levantarse del letargo y de años en que "los pueblos engañados con la promesa de una felicidad quimérica y de un progreso irrealizable, puesto que carecen de las bases sobre las cuales han descansado y tiene que descansar siempre el verdadero progreso, se encuentran lastimosamente burlados..."23.

En esta cartilla, la decisión parecía estar tomada y la guerra o confrontación declarada. Allí, se identifican como categorías propias de los liberales la civilización, progreso, bienandanza, libertad, igualdad, fraternidad. La intención que se buscaba a través del escrito era "hacer conocer las intenciones diabólicas de cuyo cambio no se ha dado a los pueblos sino el más fiero e insoportable despotismo, el despotismo de las pasiones desarregladas". ${ }^{24}$

A partir de las leyes de 1877, el liberalismo daba muestras de no querer frenar su proceso de separación de la Iglesia de las actividades del Estado. A la Iglesia no le quedaba otro camino diferente de establecer una oposición concreta ya que de allí dependía su supervivencia como estamento. A través de estos folletos, realizó su más fuerte crítica al congreso y a la expedición de la "Ley Civil en Materia de Cultos" y la ley "Por la cual se declara privados a perpetuidad del derecho de ejercer funciones de obispos a varios individuos". Esta última, privaba de ejercer funciones al obispo de Medellín y a varios curas en Antioquia. El obispo observaba cómo detrás de leyes que se apoyaban en un supuesto carácter liberal, se escondía una estrategia para atacar a la Iglesia. Por ello, se impedía a los jerarcas de la Iglesia la posibilidad de "rebatir los errores que pretenden entronizarse en la sociedad y para levantar la voz reprobándolos y condenándolos...”. Para esta fecha

23. Ibid.

24. El texto señala: "No es necesario ser profundo filósofo ni moralista consumado para saber qué es lo que se pretende hoy con las Escuelas oficiales: todos pueden ver ya el desquiciamiento de la sociedad doméstica, o sea, de la familia, el desenfreno de los pueblos en general y en particular de la juventud, y los gravísimos males que han causado las perniciosas doctrinas del liberalismo enseñadas oficialmente en las escuelas". Ibid. 


\section{EL TALLER DE LA HISTORIA 2}

el clero tenía claridad hacia dónde apuntaban las medidas de los radicales y cuál debía ser la oposición a dichas reformas. Reconocían haber participado de la guerra civil de 1875 y asumían su posición al hecho de sentirse perseguidos por el gobierno. ${ }^{25}$

A partir de 1875, Romero buscó afanosamente ligar los ataques de los radicales a la Iglesia con las creencias religiosas de la sociedad civil. Por ello, recalcaba que al atacar a la Iglesia se fomentaría "El indiferentismo religioso" logrando con ello que la religión "Santísima de Jesucristo sea despreciada y a veces se le hace objeto de escarnio y de burlas"26. Posiblemente estos hechos no sucedían en realidad. Desde la diócesis, como centro desde donde se informaba a curas sobre la situación política del Estado y de la Nación, Romero creaba con sus cartas y panfletos un estado de persecución contra la Iglesia y de alerta a los curas de las parroquias del Estado, el cual muchas veces no existía. Para Romero era claro que, a diferencia de los políticos que podían opinar y criticar las medidas económicas y políticas del gobierno, a los clérigos se les trataba discriminatoriamente. En este sentido los radicales utilizaron la ley de desamortización para expropiar y frenar el control económico y social de la Iglesia y, por otro lado, mediante la ley de "Inspección Civil", evitaban que los curas participaran en política. Sobre este carácter contradictorio de la aplicación de las leyes hacía énfasis Romero. Se preguntaba cómo era posible que, con unas leyes se les considerara como entidades privadas que debían salir del resorte de lo público y, luego con la ley de "Inspección Civil", se les prohibía participar en política, como si fueran un apéndice del Estado.

25. A.E.M. Tomo 104. Fol. 99. Enero 24 de 1878. Por ello concluía afirmando que: "Supóngase lo que no será nuevo, que un gobierno abrigue el propósito de descatolizar al país, y que sostenga y fomente periódicos con un fin nefasto: En este caso todo pastoral, sermón, discurso ó escrito de los ministros, en que se combatan aquellas miras o que se pongan de manifiesto los errores que se difunden, se estimaría como atentatorio de la seguridad y tranquilidad públicas, de acuerdo con el mencionado artículo segundo".

26. A.E.M. Tomo 112. Folio 58. Año de 1879. 
Pero el uso de panfletos y libelos no fueron exclusividad de la Iglesia. Si para la Iglesia los liberales con sus acciones se acercaban al ateísmo y encamaban el mal, los radicales también utilizaban estos pasquines para atacar a la Iglesia. Esta posición, acrítica y maniquea cerraba cualquier diálogo o confrontación ideológica y colocaba la discusión al extremo de "buenos contra malos". ${ }^{27}$

Otro de los elementos que afectó fuertemente a la Iglesia fue la prohibición a los curas del derecho al voto y a participar en política. Así lo expresaba Romero en una carta publicada en 1875. Allí, se atacaba la prohibición y se justificaba la posición política del clero por la opción contraria a la radical. En este sentido, Romero volvía a insistir en la contradicción en la que caían los radicales en sus leyes y decretos contra la Iglesia. Si esta última estaba separada del Estado, no podía exigírseles que no opinaran políticamente y, mucho menos, el derecho al sufragio. Por ello afirmaba que:

Cuando los círculos políticos de la República i del Estado, se agitan sin tregua en los debates eleccionarios, a pesar de la absoluta prescindencia que en ellos guarda nuestro clero, vamos a manifestarle nuestros deseos recomendándoles estimar consideraciones que parten de derechos inalienables, reconocidos a los asociados, cualquiera que sea la forma de gobierno que los rija. Leánse las constituciones de todos los gobiernos del mundo, i se verá que sólo hai una, que aparezca con el negro borrón de negar al clero católico, el

27. Para el año de 1876, Romero, en sus acostumbrados cuadernillos, escribía a los curas afirmando que: "Bien conocidos son de uds. los esfuerzos de los impíos de nuestros tiempos para apoderarse de la juventud i enseñarle los principios erróneos del liberalismo, doctrina infernal que por desgracia, tiene partidarios en esta República. Ellas no esquivan ningún medio para llevar a buen fin la obra de destrucción que han emprendido; sino que además crean circunstancias especiales para dar a conocer de una manera clara, sus tendencias i deseos". Este documento mostraría a un Romero menos mesurado y cercano a los discursos donde se mostraba a los liberales como enviados del diablo. El obispo abandonaba su crítica moderada y arremetía contra el liberalismo como doctrina diabólica y sus adeptos - los liberales - como hijos del demonio. Si bien Romero pocas veces hacía alusiones a los radicales utilizando metáforas que los asociaban al diablo, a nivel de los curas estas palabras eran de constante uso. A.E.M. Tomo 104. Fol. 145. Junio 30 de 1876. 
100 EL TALLER DE LA HISTORIA 2

sufrajio popular. Esa constitución nos ruborizamos al decidirlo, es la de Estados Unidos de Colombia" ${ }^{28}$.

La claridad de los argumentos de Romero hacía que la respuesta por parte de los liberales radicales fueran nulas. En este sentido, es necesario anotar que las acciones contra el clero por parte del gobierno central no fueron justificadas por parte de los gobernantes del Estado Soberano del Magdalena; simplemente aplicadas. Al final no existían argumentos para justificar acciones que simplemente buscaban acabar con el poder de la Iglesia Católica y de su principal aliado político, el partido conservador.

28. A.E.M. Tomo 108. Fol. 00069. Abril 17 de 1875. Circular $\mathrm{N}^{£} 40$. Del obispo a los curas. Tipografía Mercantil de Santa Marta. 